\title{
Pediatric Aerosol Therapy
}

\author{
Ariel Berlinski MD
}

\author{
Introduction \\ Delivery Device Selection for the Treatment of Acute Pediatric Asthma \\ Transnasal Aerosol Delivery in Pediatric Patients \\ Delivery Device Selection for Spontaneously Breathing Tracheostomized \\ Children \\ Delivery Device Selection for Pediatric Patients Receiving NIV \\ Delivery Device Selection for Mechanically Ventilated Pediatric Patients \\ Summary
}

\begin{abstract}
Inhaled medications are the mainstay of therapy for many pediatric pulmonary diseases. Device and delivery technique selection is key to improving lung deposition of inhaled drugs. This paper will review the subject in relationship to several pediatric clinical situations: acute pediatric asthma, transnasal aerosol delivery, delivery through tracheostomies, and delivery during noninvasive and invasive mechanical ventilation. This review will focus on the pediatric age group and will not include neonates. Key words: nasal cannula; noninvasive ventilation; NIV; nebulizer; metered dose inhaler; nasal delivery; children; valved holding chamber; HFNC; albuterol; mechanical ventilation. [Respir Care 2017;62(6):662-677. (C) 2017 Daedalus Enterprises]
\end{abstract}

\section{Introduction}

Inhaled medications are the mainstay of therapy for many pediatric pulmonary diseases. These therapies are given to patients who receive different types of respiratory support. Improvements in survival and development of new technologies have also changed the prognosis of many pediatric pulmonary conditions. This heterogeneous population includes pediatric patients with asthma (maintenance therapy and rescue therapy during exacerbations), patients with respiratory distress requiring invasive mechanical ventilation or noninvasive ventilation (NIV) support, pediatric

Dr Berlinski is affiliated with the Pulmonary Medicine Section, Department of Pediatrics, College of Medicine, University of Arkansas for Medical Sciences, Little Rock, Arkansas and the Pediatric Aerosol Research Laboratory, Arkansas Children's Research Institute. Little Rock, Arkansas.

Dr Berlinski has disclosed relationships with Vertex, Cempra, AbbVie, Allergan, Genentech, Janssen, Gilead, Teva, Philips, Novartis, National Institutes of Health, and Therapeutic Development Network. Dr Berlinski is a Science Advisor to the Device Human Factors Subgroup of the International Pharmaceutical Aerosol Consortium on Regulation and Science (IPAC-RS). patients requiring transnasal support in the form of highflow nasal cannula (HFNC), and spontaneously breathing tracheostomized pediatric patients. ${ }^{1-5}$ Although pediatric patients with other conditions, such as cystic fibrosis, also use different inhaled drugs, their discussion is outside of the scope of this paper.

Many aerosol delivery devices are available to deliver inhaled aerosols to children. Nebulizers, pressurized metered-dose inhalers (pMDIs), soft mist inhalers, and dry powder inhalers for different drugs are available on the market. Many inhaled drugs are used off label in pediatric patients because they are used for either a different indication or a younger age group, or because they are deliv-

Dr Berlinski presented a version of this paper at the 55th RESPIRATORY CARE Journal Conference, "Pediatric Respiratory Care," held June 10 11, 2016, in St Petersburg, Florida.

Correspondence: Ariel Berlinski MD, 1 Children's Way, Slot 512-17, Little Rock, AR 72202. E-mail: berlinskiariel@uams.edu.

DOI: $10.4187 /$ respcare. 05298 
Table 1. Inhalation Devices Available on the Market

\begin{tabular}{l}
\hline \hline Pressurized metered-dose inhaler with valved holding chamber \\
Soft mist inhaler \\
Breath-actuated dry powder inhaler \\
Dry powder inhaler \\
Jet nebulizer \\
Continuous-output \\
Breath-enhanced \\
Breath-actuated \\
Ultrasonic nebulizer \\
Vibrating mesh nebulizer \\
\hline
\end{tabular}

ered through artificial airways and different respiratory support devices. ${ }^{6}$ The optimal particle size of aerosols that will enhance intrapulmonary deposition in pediatric patients breathing through either artificial airways or the oronasal region is unknown. ${ }^{7}$

Since radiolabeled deposition and pharmacokinetic studies of inhaled drugs are challenging in children, most of the available data come from in vitro studies. Besides their inherent limitations, the difference in experimental setups makes comparisons across studies a challenging matter. Practitioners need to carefully review the setups and should not extrapolate results from one model to another. In addition, the reader needs to be mindful when reviewing studies that compare devices that use different loading doses that the absolute lung dose is the most useful outcome measure.

This paper reviews the available literature regarding each of the conditions/clinical situations described previously. This review will focus on the pediatric population with the exception of the neonatal group. Whenever pediatric data are missing, relevant adult data will be presented.

\section{Delivery Device Selection for the Treatment of Acute Pediatric Asthma}

Pediatric asthma is a highly prevalent disease, and most patients receive a preventive and a rescue inhaled regimen. ${ }^{1}$ These medications are available in different formulations, such as nebulizer solution/suspensions and those contained in pMDIs and dry powder inhalers. Several types of inhalation devices are available on the market (Table 1). Knowing how to use these devices is crucial to deliver effective therapy. Several studies have repeatedly shown poor knowledge among health-care practitioners about how to operate aerosol delivery devices. ${ }^{8,9}$ This section will focus on drug delivery during a pediatric asthma exacerbation. A systematic review and meta-analysis comparing nebulization versus pMDI and valved holding chamber (VHC) in children younger than $5 \mathrm{y}$ of age presenting with a moderate to severe wheezing/asthma exacerbation favored the use of $\mathrm{pMDI} / \mathrm{VHC} .^{10}$ The review included 6 clinical trials and 491 subjects. Subjects treated with $\mathrm{pMDI} / \mathrm{VHC}$ were less likely to be admitted (odds ratio 0.42 ), especially those presenting more severe symptoms (odds ratio 0.27 ). Moreover, severity scores showed greater improvement in those subjects receiving $\mathrm{pMDI} / \mathrm{VHC}$ than in those receiving nebulization. A Cochrane review ${ }^{11}$ concluded that $\mathrm{pMDI} / \mathrm{VHC}$ can perform at least as well as wet in delivering bronchodilators to children presenting with acute asthma. The review included 1,897 children and 39 clinical trials, with 6 of them done in an in-patient setting. The review showed that although admission rates and lung function testing were similar between $\mathrm{pMDI} / \mathrm{VHC}$ and nebulization, the former showed a shorter stay in the emergency department.

Device selection is a complex process that is influenced by multiple variables, most of them out of our control. Clear examples of these limitations are: (1) drug availability, (2) device availability, (3) ease of use, (4) acceptability by the family, (5) cost, and (6) patient cooperation. The variable we control is our knowledge of the device characteristics and whether they will match the needs of the patients under our care. For example, when using either a breath-enhanced or a breath-actuated jet nebulizer or a breath-actuated dry powder inhaler, we need to verify that the patient can trigger the device. Changes in the reimbursement models from fee for service to bundle payments and episodes of care with financial co-responsibility are severely influencing the choice of devices/formulations used in the emergency departments and other hospital settings. The cost of treatment comprises several variables: (1) cost of the device, (2) cost of the drug, (3) cost of the add-on device if required (eg, VHC), and (4) cost of the respiratory therapist time (Table 2). The latter has led many institutions to use continuous albuterol therapy instead of intermittent treatments. Many institutions are going back to using small-volume jet nebulizers in their emergency department after many years spent transitioning from nebulizer to pMDI/VHC therapy due to the high cost of the pMDIs that use hydrofluoroalkane as a propellant. ${ }^{12}$ Also, many have restricted the use of $\mathrm{pMDI} / \mathrm{VHC}$ when multiple doses are prescribed because of the recommendation of waiting 1 min between actuations present in the package insert of the pMDI albuterol commercially available in the United States. ${ }^{13-15}$ However, recently, an in vitro study showed that there were no differences in the aerosol characteristics of any of the 3 albuterol pMDIs when used with a small-volume nonelectrostatic VHC and actuated at $15-, 30-$, and 60-s intervals, provided the inhaler was shaken right before actuation. ${ }^{16}$

In summary, both nebulizers and pMDI/VHC are effective in delivering bronchodilators to children experiencing acute bronchoconstriction. The choice of device appears to be heavily influenced by cost in the emergency department and in-patient settings. Continued educational efforts will 
Table 2. Cost of Delivering Bronchodilators at Health-Care Facilities

\begin{tabular}{|c|c|c|c|c|}
\hline System & Device & Add-on & Drug & Respiratory Therapist Time \\
\hline Pressurized metered-dose inhaler and valved holding chamber & NA & ++ & ++++ & ++ \\
\hline Small-volume jet nebulizer & + & NA & + & +++ \\
\hline Large-volume jet nebulizer & ++ & NA & + & ++ \\
\hline Breath-enhanced/actuated jet nebulizer & ++ & NA & + & ++ \\
\hline Vibrating mesh nebulizer & +++++ & +++ & + & + \\
\hline
\end{tabular}

be required to reassure patients/caregivers of the equivalence of $\mathrm{pMDI} / \mathrm{VHC}$ and nebulizers.

\section{Transnasal Aerosol Delivery in Pediatric Patients}

The nose and the upper airway serve several purposes, including humidification and filtering inhaled air. Infants and children younger than 18 months of age are obligate nasal breathers, resulting in loss of delivery efficiency of inhaled aerosols. There has been a significant interest over recent years in using the transnasal route to deliver aerosols to children and in particular for those receiving respiratory support with HFNC systems. Most of the knowledge derives from in vitro studies. Some in vivo studies have also provided insight into the role of the aerosol characteristics in lung deposition in this age group.

Chua et al ${ }^{17}$ compared intrapulmonary deposition of a radiolabeled aerosol in children with cystic fibrosis. The study included 2 age groups (mean ages of 0.8 and $10.8 \mathrm{y}$ old). They reported that during nasal breathing, lung deposition was 1.3 and $2.7 \%$ for the younger and older group, respectively. In addition, when the older group was instructed to breathe orally, lung deposition rose to $6.3 \%$. Amirav et al ${ }^{18}$ compared lung deposition of a radiolabeled solution (mass median aerodynamic diameter [MMAD] $3 \mu \mathrm{m})$ in 12 infants when using a conventional mask and when using a proprietary low-volume mask that allowed the pacifier to be suckled during the therapy. They found no differences in deposition in the right lung (1.6-1.7\%). The authors measured only the right lung to avoid interference with the esophagus and the stomach. Mallol et al ${ }^{19}$ evaluated lung deposition of a radiolabeled solution in infants with cystic fibrosis. They reported lung deposition of 0.76 and $2.0 \%$ with aerosols of MMAD 7.7 and $3.6 \mu \mathrm{m}$, respectively. They also reported that lung deposition was central with the aerosol with large MMAD and peripheral with the aerosol with small MMAD. Similar results were reported by Schuepp et al, ${ }^{20}$ delivering radiolabeled budesonide to 6 young children (average age 34 months). They compared a breath-enhanced nebulizer (MMAD $4.2 \mu \mathrm{m}$ ) with a vibrating mesh nebulizer (MMAD $2.5 \mu \mathrm{m}$ ) and found that the aerosol with the smaller MMAD had 4.6- fold more deposition than the one with large MMAD. In summary, these in vivo studies demonstrated that aerosols of smaller particle size result in higher and more peripheral lung deposition and that although the nasal route results in decreased lung dose, it is the main inhalation route for young children. ${ }^{17-20}$

Many in vitro studies have researched transnasal delivery of aerosols in infants and children. ${ }^{21-28}$ Amirav et al ${ }^{21}$ compared nasal and oral delivery in pediatric models of 5-, 14-, and 20-month-old infants and toddlers. They used a soft mist inhaler coupled to a nonelectrostatic valved holding chamber with a soft, low-deadspace volume mask. They reported that the nasal delivery route was higher than oral delivery for the 5- and 14-month-olds tested with low and high tidal volumes. However, delivery efficiency was similar between routes for the 20-month-old model. Xi et $\mathrm{al}^{22}$ utilized computational fluid dynamic methods and compared different parameters in the nasolaryngeal airways of anatomically correct models of 10-d-old, 7-monthold, 3-y-old, and 5-y-old children and a 63-y-old adult. They reported significant age-related differences in total and regional deposition as well as in anatomical parameters.

El Taoum et $\mathrm{al}^{23}$ compared transnasal albuterol aerosol delivery using a simulated breathing technique and anatomically correct airway models. They compared a vibrating mesh nebulizer (Aeroneb Go, Aerogen, Galway, Ireland) and a continuous-output jet nebulizer (Hudson Optineb, Teleflex Medical, Research Triangle Park, North Carolina) used in conjunction with different interfaces. They used breathing patterns with tidal volumes of 25 , 50 , and $155 \mathrm{~mL}$; breathing frequencies of 40,30 , and 25 breaths/min; and inspiratory-expiratory ratios (I:E) of 1:3, $1: 3$, and 1:2. They reported an average lung dose of 0.51 , 1.05 , and $0.97 \%$ with the jet nebulizer $(6 \mathrm{~L} / \mathrm{min})$ delivered via transnasal route for the breathing patterns with tidal volumes of 25,50 , and $155 \mathrm{~mL}$, respectively, with the 7-month-old model. Lung deposition, with the same device and route, reached an average of 0.44 and $1.14 \%$ for the $50-$ and $155-\mathrm{mL}$ tidal volume breathing patterns, respectively, with the 5-y-old model. The vibrating mesh was only able to deliver a measurable lung dose with one 
of the interfaces, reaching values of 0.13 and $0.84 \%$ (7month-old model) and 0 and $0.42 \%$ (5-y-old model) for the breathing patterns with tidal volumes of 50 and $155 \mathrm{~mL}$. Lung dose achieved with a tightly sealed front loading mask and jet nebulizer reached 2.97, 1.52, and $0.60 \%$ (7-month-old model) for the breathing patterns with tidal volumes of 25,50 , and $155 \mathrm{~mL}$, respectively.

Berlinski and $\mathrm{Xi}$ characterized, with a cascade impactor (Next Generation Impactor, MSP, Shoreview, Minnesota), nebulized aerosols inhaled via the nasal and oronasal route through an anatomically correct model of a 5-y-old child. ${ }^{24}$ They reported that the nasal mode resulted in a larger percentage of particles $<5 \mu \mathrm{m}(97 \%$ vs $90 \%)$ and between 1 and $3 \mu \mathrm{m}(49 \%$ vs $38 \%)$ than the oronasal route. No changes were noted in the MMAD (2.72 $\mu \mathrm{m}$ vs $2.84 \mu \mathrm{m})$ and geometric standard deviation (GSD) (1.67 vs 1.58). The nebulizer alone had different characteristics $(\mathrm{MMAD}=4.67 \mu \mathrm{m}, \mathrm{GSD}=2.14$, percentage of particles $<5 \mu \mathrm{m}=53 \%$, and percentage of particles $1-3 \mu \mathrm{m}=$ $21 \%) .{ }^{25}$ In another study, Cooper and Berlinski ${ }^{26}$ compared particle size aerosol generated by pMDI and 2 different VHCs (Aerochamber Mini and Aerochamber, Monaghan Medical, Plattsburg, New York) using the same anatomically correct model of a 5-y-old child. They found that the aerosol characteristics of pMDI/VHC were similar between traditional measurements and measurements done through the oronasal route of the model (MMAD $=2.15 \mu \mathrm{m}$ vs $1.90 \mu \mathrm{m}$, GSD $=1.45$ vs 1.65 , and mass associated with particles $<5 \mu \mathrm{m}$ of $99 \%$ for all).

Janssens et $\mathrm{al}^{27}$ reported that increasing the tidal volume during inhalation of budesonide pMDI resulted in a progressive decreased in the lung dose when tested in an anatomically correct model of a 9-month-old infant. Janssens et al, using the same model, compared lung deposition of 2 formulations of beclomethasone dipropionate and found that lung dose with the hydrofluoroalkane beclomethasone (MMAD $=1.1-1.3 \mu \mathrm{m}$ ) was several-fold higher than with chlorofluorocarbon beclomethasone $($ MMAD $=2.6-3.3 \mu \mathrm{m}) .{ }^{28}$ These in vitro studies support the conclusions reached by the clinical studies. ${ }^{17-28}$

Bhashyam et $\mathrm{al}^{29}$ investigated aerosol delivery of a radiolabeled aerosol generated by a vibrating mesh nebulizer (Solo, Aerogen, Galway, Ireland) placed on the wet side of the humidifier of an HFNC system (Fisher \& Paykel Healthcare, Auckland, New Zealand) operated at $3 \mathrm{~L} / \mathrm{min}$. They used a non-anatomically correct model and ran the experiments with and without simulated breathing (tidal volumes of 150,300 , and $550 \mathrm{~mL}$; breathing frequency of 25 , 18 , and 15 breaths/min; and I:E of 1:1). The delivered dose was $18.6,25.4$, and $26.9 \%$ for the neonatal, pediatric, and adult cannula, respectively, when tested with simulated breathing. A lower delivered dose was reported when simulated breathing was not used $(8.4,18.1$, and $25.1 \%$ for the neonatal, pediatric, and adult cannula, respectively). The authors measured particle size of aerosols exiting the pediatric and adult size cannulas using a laser diffraction technique. They reported a volume median diameter of 1.9 and $2.2 \mu \mathrm{m}$ with $90 \%$ of the aerosol contained in particles smaller than 3.8 and $4.2 \mu \mathrm{m}$ for the pediatric and the adult cannulas, respectively. The losses in the heated circuit and in the connector between the heater and the nebulizer were 31.4 and $23 \%$ for the neonatal cannula and 36.2 and $26.6 \%$ for the pediatric cannula. These losses were not affected by the use of breathing simulation. Streamlining of the connectors using computational fluid dynamics could help enhance aerosol delivery. ${ }^{30}$

Ari et al investigated aerosol albuterol delivery with a vibrating mesh nebulizer (Solo, Aerogen, Galway, Ireland) placed on the dry side of the HFNC system operated at 3 and $6 \mathrm{~L} / \mathrm{min}$ with either oxygen $(100 \%)$ or heliox (heliumoxygen mixture) (80/20). ${ }^{31}$ They used a non-anatomically correct model and a breathing simulator with a pediatric pattern (tidal volume $100 \mathrm{~mL}$, breathing frequency 20 breaths/min, and I:E of 1:2). The authors reported delivered doses of 10.7 and $2 \%$ ( 3 and $6 \mathrm{~L} / \mathrm{min}$ ) and 11.4 and $5.4 \%$ ( 3 and $6 \mathrm{~L} / \mathrm{min}$ ) when using $100 \%$ oxygen or heliox $80 / 20$, respectively. The increase in flow decreased delivered dose, and the use of heliox improved delivered dose only at the highest tested flow.

Perry et al ${ }^{32}$ investigated the effect of cannula size and flow on albuterol delivery when a vibrating mesh nebulizer (Solo, Aerogen, Galway, Ireland) and an HFNC system (Vapotherm 2000i, Stevensville, Maryland) were used. They used a non-anatomically correct airway model. The nebulizer was placed proximal to the nasal cannula. They evaluated 3 different sizes of cannulas with the system operated at different flows. The breathing simulator was set at 50-, 155-, and 500-mL tidal volumes and 1:2, 1:2, and 1:1 I:E ratios for the infant, pediatric, and adult cannula, respectively. They reported that the inspired dose was very low, with an average of $0.6 \%$ for the infant model (flows 3-8 L/min). They found that the inspired dose was 1.2 and $0.6 \%$ when using the pediatric model with flows of 3 and $5 \mathrm{~L} / \mathrm{min}$, respectively. The inhaled dose dramatically decreased with the use of $10 \mathrm{~L} / \mathrm{min}$ (almost nil). The adult model showed the highest inhaled dose at $5 \mathrm{~L} / \mathrm{min}(2.5 \%)$. The delivered dose decreased to one third when the flow was increased to $10 \mathrm{~L} / \mathrm{min}$. They also reported that under all tested conditions, the amount of drug remaining in the adapter ranged from 60 to $80 \%$. The authors also characterized the particle size using cascade impaction and reported a mass median aerodynamic diameter between 0.48 and $1.38 \mu \mathrm{m}$ with flows between 3 and $10 \mathrm{~L} / \mathrm{min}$. The reported geometrical SD values were extremely large (4.5-15 range). The respiratory fraction ranged from 73 to $90 \%$ for the same flows. They also reported that for low flows ( $3-5 \mathrm{~L} / \mathrm{min})$, the percentage of particles $<0.5 \mu \mathrm{m}$ ranged from 40 to $50 \%$. 
Réminiac et al $^{33}$ studied aerosol delivery using vibrating mesh and jet nebulizers placed in different positions of an HFNC system (Fisher \& Paykel 850, Fisher \& Paykel Healthcare, Auckland, New Zealand) assembled with an adult circuit. The authors studied several flows, but I will only discuss their results at their lowest tested flow $(30 \mathrm{~L} / \mathrm{min})$. Although they used an adult model, their study provided some insight into the effect of the experimental setup and the results obtained. They reported similar drug delivery between different nebulizers when they were placed before the humidifier. The small particle jet nebulizer delivered a monodisperse aerosol (GSD $=0.9$ ) with an MMAD of $0.5 \mu \mathrm{m}$ and with $69 \%$ of drug mass contained in particles $<0.4 \mu \mathrm{m}$. Delivered dose decreased from 26 to $6.7 \%$ when simulated breathing and an anatomically correct upper airway model were used (vibrating mesh placed before the humidifier). Delivered dose further decreased to $4.7 \%$ when a mouth open situation was simulated. These findings underscore the need for carefully reviewing the experimental setup to be able to critically assess the results reported for in vitro experiments.

Réminiac et al recently presented pediatric in vitro data using an anatomically correct 9-month-old infant model. ${ }^{34}$ The authors used a heated-cannula system (Fisher \& Paykel 850, Fisher \& Paykel Healthcare, Auckland, New Zealand) with a vibrating mesh nebulizer (Solo, Aerogen, Galway, Ireland) and a jet nebulizer (Cirrus2, Intersurgical, East Syracuse, New York) placed on the dry side of the humidifier connected to a breathing simulator (tidal volume $=25 \mathrm{~mL}$, breathing frequency $=40$ breaths $/ \mathrm{min}$, and I:E 1:2). The vibrating mesh nebulizer was tested with HFNC flows of 2,4 , and $8 \mathrm{~L} / \mathrm{min}$. The jet nebulizer, operated at $6 \mathrm{~L} / \mathrm{min}$, was tested with face mask alone, with face mask and $2 \mathrm{~L} / \mathrm{min} \mathrm{HFNC}$, and on the dry side of the humidifier with the HFNC running on $2 \mathrm{~L} / \mathrm{min}$. They reported a delivered dose of $4.2,3.3$, and $0.5 \%$ for the vibrating mesh nebulizer with flows of 2,4 , and $8 \mathrm{~L} / \mathrm{min}$, respectively. They also reported a delivered dose of 1.7 , 0.9 , and $0.5 \%$ for the jet nebulizer with face mask alone, with face mask with HFNC at $2 \mathrm{~L} / \mathrm{min}$, and when placed on the dry side of the humidifier, respectively.

These in vitro data underscore the critical role that cannula size and flow play during aerosol delivery through HFNC in pediatric models. ${ }^{29,31-34}$ They also show that the flow used by the HFNC system adversely affects drug delivery. Patients with moderate to severe distress receiving HFNC support in the high end of the flow range (6$8 \mathrm{~L} / \mathrm{min}$ ) will receive a minimal lung dose. Therefore, practitioners may need to increase the loading dose to compensate for the inefficiency of the delivery, while at the same time they should monitor for adverse effects.

An anecdotal report of relief of upper-airway obstruction due to croup by epinephrine delivered through an HFNC system was followed by in vitro testing. ${ }^{35}$ Leung et $\mathrm{al}^{36}$ evaluated the feasibility of delivering epinephrine $(30 \mathrm{mg} / \mathrm{L}$ ) in the vapor phase of an HFNC system (Vapotherm I, Exeter, New Hampshire). They tested the system at 5,10 , and $15 \mathrm{~L} / \mathrm{min}$. They reported a $4-5$-fold dilution of the initial concentration of the epinephrine solution. They also reported a drug delivery rate of 1.8, 3.6, and $4.2 \mu \mathrm{g} / \mathrm{min}$ for the 5,10 , and $15 \mathrm{~L} / \mathrm{min}$, respectively.

Farney et $\mathrm{al}^{37}$ evaluated aerosol delivery of a radiolabeled solution using a vibrating mesh nebulizer connected to variable flow nasal CPAP system (Infant Flow SiPAP, CareFusion, San Diego, California) and heated-wire circuit (RT324, Cardinal Health, Dublin, Ohio). The nebulizer was placed at 2 different positions: (1) between the circuit and the nasal cannula and (2) on the wet side of the humidifier. The CPAP was set to a pressure of $6 \mathrm{~cm} \mathrm{H}_{2} \mathrm{O}$, and the test lung was set to deliver a tidal volume of $45 \mathrm{~mL}$. They reported a lung deposition of $20 \%$ and $<1 \%$ deposition for positions 1 and 2, respectively. They also reported that about $60 \%$ of the aerosol was deposited in the heated-wire system. A potential problem with position 1 is that patient movement can cause spilling of the contents of the nebulizer.

Although published pediatric data are lacking, studies performed in adults have reported that a proprietary device (transnasal pulmonary aerosol delivery, tPAD, Parion Sciences, Durham, North Carolina) was able to generate lung deposition of $7 \%$ hypertonic saline similar to that via a breath-enhanced nebulizer (Pari LC Star, PARI GmbH, Starnberg, Germany) in healthy adults. ${ }^{38}$ The radiolabeled study demonstrated a more peripheral distribution of the aerosol generated by tPAD. A study evaluating the mucociliary clearance of subjects with cystic fibrosis after receiving 8-h overnight transnasal therapy was completed (ClinicalTrials.gov registration NCT02141191). Their patent (United States 20140109899 A1) claims that the aerosol has a VMD from 0.5 to $2.5 \mu \mathrm{m}$ with no more than $10 \%$ of aerosol $>4 \mu \mathrm{m}$ that results in a $>3 \%$ deposition efficiency. ${ }^{38}$ The internal diameter of the nozzles of the cannula were either 2.5 or $3 \mathrm{~mm}$. More recently, Morgan et $\mathrm{al}^{39}$ reported a case series of infants treated with HFNC and albuterol and reported that delivery through the cannula system led to a significantly higher heart rate than when delivered through a face mask.

New approaches to improve aerosol delivery during use of HFNC include 2 techniques described by Longest et al. ${ }^{40,41}$ They both include the use of submicronic particles that experience hygroscopic growth as they travel through the airways. The advantage of these techniques is that their small starting particle size minimizes upper-airway deposition. The excipient enhance growth method uses hygroscopic excipients (ie, mannitol) mixed with submicronic particles that experience growth as they are in contact with the humid environment of the airways, reaching then a particle size optimal for intrapulmonary depo- 
sition. ${ }^{40}$ The other method, enhanced condensational growth, uses a modified cannula to independently deliver humid flow through one prong and dry flow carrying the submicronic particles on the other. ${ }^{41}$ Hygroscopic growth progressively occurs upon admixture of both flows. These 2 new techniques need to be validated on animal models and in humans before being ready for prime time.

In summary, aerosol delivery via the transnasal route is a growing field. More data are required before it can be recommended for general use. Early adopters need to be aware of the deleterious effect of high-flow and smalldiameter nasal prongs on drug delivery. Practitioners should consider that lack of clinical response with these systems could potentially represent lack of adequate drug delivery. When deciding placement of the device in the circuit, practitioners should not only consider deposition data but also practical aspects, such as weight of the device and whether it will remain operational with movement/rotation of the infant.

\section{Delivery Device Selection for Spontaneously Breathing Tracheostomized Children}

Improvement in life support technologies and better understanding of patient-technology interactions have led to increased survival in critically ill infants and children. A group of them are tracheostomy-dependent, and a subset of those children also require some form of respiratory support. ${ }^{42}$ Many of these patients also require inhaled therapy for their maintenance and rescue therapy. ${ }^{4}$ The presence of the artificial airway adds factors that could hinder aerosol delivery in that population.

Our current understanding of drug delivery in spontaneously breathing tracheostomized infants and children is based on limited in vivo data and few in vitro studies. ${ }^{26,43-49}$ Very little guidance about drug delivery is currently available. ${ }^{50,51}$ In vitro studies done with adult models showed that tracheostomy delivery is more efficient than delivery through endotracheal tubes (ETTs). ${ }^{52}$ Therefore, extrapolating data from drug delivery through mechanical ventilation would be inaccurate.

Baran et $\mathrm{al}^{43}$ studied drug delivery of gentamicin (intramuscular injection, endotracheal instillation, and aerosolization) in 6 pediatric tracheostomized subjects. Sputum and blood gentamycin concentration were measured $1 \mathrm{~h}$ after administration. Instillation and aerosolization resulted in sputum concentrations 451- and 19-fold higher than the intramuscular administration. They also reported that the intramuscular and endotracheal administration resulted in blood levels 79- and 28-fold higher than the aerosolized route.

Lewis and McCaig ${ }^{44}$ compared lung deposition of nebulized versus instilled surfactant in a sheep model of nonuniform pattern of lung injury during mechanical ventila- tion. They reported that the nebulized method provided a more uniform distribution of the surfactant than the instillation. The authors recovered 31.8 and $63.1 \%$ of the nebulized and instilled surfactant, respectively. These studies underscore the significant differences in tracheal and systemic dose as well as intrapulmonary distribution achieved by inhalation and instillation through tracheostomies.

Willis and Berlinski ${ }^{4}$ reported a survey of aerosol practices in spontaneously breathing tracheostomized pediatric subjects. Their data documented the presence of a significant variation in practices among different institutions. They found that $92 \%$ of the responders used pMDIs and that $68 \%$ of them either exclusively or sometimes used assisted technique. They also found that $97 \%$ of the responders used nebulizers and that $32 \%$ of them used assisted technique. Short-acting $\beta$ agonist, corticosteroids, mucolytics, and antibiotics were used by at least $82 \%$ of the responders.

In vitro studies have looked into the effect on drug delivery of several variables (inner diameter [ID] of the tracheostomy tube, type of aerosol generator, type of MDI formulation, breathing pattern, use of assisted technique, interface, and use of bias flow). ${ }^{26,45-49}$

Berlinski and Chave $\mathrm{z}^{45}$ compared albuterol delivery via pMDI/add-on devices in a model of a spontaneously breathing (tidal volumes of 80,155 , and $310 \mathrm{~mL}$ ) tracheostomized child when using tracheostomy tubes with IDs of $3.5,4.5$, and $5.5 \mathrm{~mm}$ and a direct connection. They reported that reducing tracheostomy ID from 4.5 to $3.5 \mathrm{~mm}$ but not from 5.5 to $4.5 \mathrm{~mm}$ resulted in a significant decrease in lung dose. ${ }^{45}$ The add-on devices ranked in efficiency as follows: Aerotrach (nonelectrostatic VHC), followed by Aerochamber MV (spacer), Aerochamber Mini (nonelectrostatic VHC), and the inline adapter. They also found that in general, larger tidal volumes were associated with larger lung dose than smaller tidal volumes. The use of assisted technique resulted in a reduction of delivered dose $(18-67 \%)$. The authors reported that a median of $7.4 \%$ was retained in the tracheostomy tube.

In another study, using the same model (tidal volume 80 and $310 \mathrm{~mL}$ and tracheostomy ID 3.5 and $5.5 \mathrm{~mm}$ ) with direct connection, Berlinski ${ }^{46}$ compared 3 different types of jet nebulizers. The breath-enhanced nebulizer ranked first for efficiency followed by the continuous-output and the breath-actuated nebulizers. The study also demonstrated that the breath-enhanced nebulizer and the continuousoutput jet nebulizer with the addition of corrugated tubing and supported by assisted technique had the greatest tracheal deposition. These devices could potentially be used to treat intra-tracheal infections. They reported that larger tidal volumes resulted in higher drug delivery than lower tidal volumes and that the T-piece was a more efficient interface than the tracheostomy mask. The author also measured the particle size of aerosols exiting the tip of the 
tracheostomy tube and found a $48-74 \%$ reduction in MMAD that resulted in the $1.20-1.77-\mu \mathrm{m}$ range for the tested scenarios. Only $0.8 \%$ of the nominal dose was deposited in the tubes.

Alhamad et $\mathrm{al}^{47}$ compared a vibrating mesh and a continuous-output jet nebulizer with a pMDI with a spacer in a pediatric model (tidal volume $150 \mathrm{~mL}$ ) with sideways connection using a tracheostomy with an ID of $4.5 \mathrm{~mm} .{ }^{48}$ The vibrating mesh nebulizer delivered 3-fold more albuterol than the other 2 systems. The authors also tested the use of assisted technique and found no difference in delivered dose.

Cooper and Berlinski ${ }^{26}$ using a different pediatric model (tidal volumes 50,155 , and $300 \mathrm{~mL}$ with tracheostomy ID 3.5 and $4.5 \mathrm{~mm}$ ) compared albuterol delivery generated by a continuous-output jet nebulizer and a pMDI with 2 different valved holding chambers. In addition, the use of assisted technique was tested. The authors also evaluated albuterol delivery through the oronasal route in an anatomically correct model of a 5-y-old child. The authors found an increase in delivered dose with increase in tidal volume that plateaued at $155 \mathrm{~mL}$. The use of assisted technique slightly increased delivered dose with the nebulizer but remained unchanged or decreased with pMDI. The authors reported that reducing the ID of the tracheostomy resulted in a lower delivered dose for both nebulizer and pMDI. They found the Aerochamber Mini to be more efficient than the Aerotrach. The authors measured particle size of the pMDI aerosols exiting the tip of a tracheostomy with ID of $4.5 \mathrm{~mm}$ using a methodology described previously. ${ }^{46}$ They reported a $19-23 \%$ reduction in MMAD. The tube retained $<4 \%$ and $<26 \%$ of the nominal drug for the nebulizer and pMDI, respectively. They also reported that changing the delivery route from an oronasal to a tracheostomy route resulted in an increase of the lung dose for the nebulizer but had variable effects on the $\mathrm{pMDI} / \mathrm{VHC}$.

In a subsequent study, Berlinski and Cooper ${ }^{48}$ used the same model as Cooper and Berlinski ${ }^{26}$ and compared albuterol delivery with a pMDI and soft mist inhaler attached to a metallic VHC (Vortex Tracheo, PARI, Starnberg, Germany) through the oronasal and tracheostomy route. They found that in most scenarios the soft mist inhaler delivered more albuterol than the pMDI. ${ }^{48}$ They also reported that in general, changing an oronasal to a tracheostomy route results in an increase of the delivered dose. The authors also reported that tidal volumes of 155 and $300 \mathrm{~mL}$ resulted in higher tracheostomy delivery than a tidal volume of $50 \mathrm{~mL}$ for both formulations. A tidal volume of $300 \mathrm{~mL}$ had higher delivered dose than a tidal volume of $150 \mathrm{~mL}$ when the soft mist inhaler was used. The amount retained in the tracheostomy tube was 2-5fold higher for the soft mist inhaler than for the pMDI.

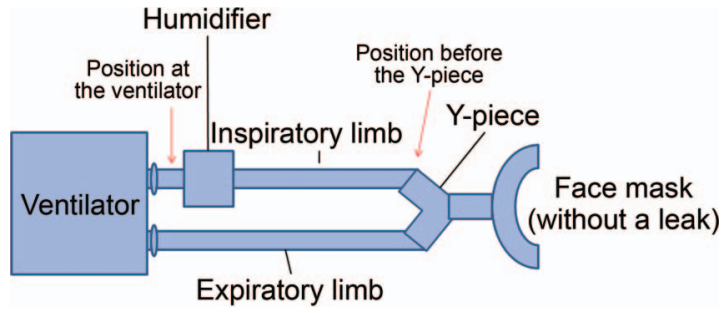

Fig. 1. Diagram of a dual-limb ventilator circuit used during noninvasive ventilation. From Reference 55, with permission.

Studies in adult models reported that the addition of bias flow decreased drug delivery through tracheostomies. ${ }^{49}$ Their effects are likely to be present in pediatric models as well.

In summary, these studies show that in general: (1) nebulizers, pMDI, and soft mist inhalers can deliver aerosol through tracheostomies; (2) tracheostomies with large ID facilitate drug delivery and an ID $<4.5 \mathrm{~mm}$ hinders drug delivery; (3) breathing patterns with large tidal volumes enhance drug delivery; (4) the use of assisted technique decreases lung delivery of pMDIs/VHC but results in increased tracheal deposition when nebulizers are used; (5) the use of bias flow hinders drug delivery; and (6) aerosols experience change in their characteristic when traveling through a tracheostomy tube, and the changes are more pronounced for those generated by nebulizers than $\mathrm{pMDI} / \mathrm{VHC}$.

\section{Delivery Device Selection for Pediatric Patients Receiving NIV}

Noninvasive ventilation is increasingly being used in the pediatric population to treat respiratory distress and respiratory failure. ${ }^{53,54}$ Many of these patients also receive inhaled therapy. Therefore, it is clinically relevant for practitioners to know how to optimize aerosol delivery in that clinical situation. The 2 most common clinical scenarios that practitioners face are children being extubated to NIV and children with worsening respiratory distress, where NIV is used to avoid intubation and invasive mechanical ventilation. Most new ventilators have NIV modalities, so it is highly likely that in the first case scenario, a dual-limb ventilator circuit would be used during NIV (Fig. 1). ${ }^{55}$ During this case scenario, the mask and connector should not have a leak.

However, many devices also use a single limb ventilator that incorporates a leak in the circuit near the patient and/or in the mask (Fig. 2). ${ }^{55}$ The relationship between the position of the aerosol generator and the leak is crucial because aerosol may leave the circuit before even reaching the patient when placed before the leak. Practitioners should keep in mind when using ipratropium bromide that the use 


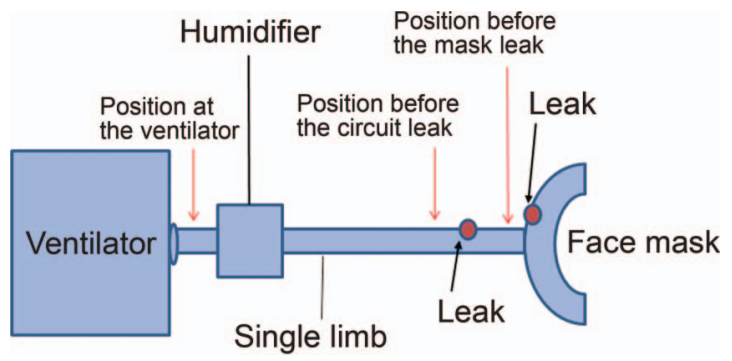

Fig. 2. Diagram of a single-limb ventilator circuit used during noninvasive ventilation. From Reference 55, with permission.

of a mask could generate ocular exposure and result in mydriasis. ${ }^{56}$ Simonds et al ${ }^{57}$ studied whether adult subjects (healthy, with coryzal symptoms, and with chronic lung disease admitted with an infective exacerbation) generated droplets during NIV and other respiratory care procedures. They compared a vented mask with a modified mask that incorporated a filter and found that the latter prevented droplet dispersion. When using vented masks, droplets deposited up to $1 \mathrm{~m}$ from the source. Also, the use of NIV in healthy subjects did not lead to an increase in droplet formation. These data are very relevant when planning for mass casualty scenarios involving respiratory infections and use of NIV.

In contrast to aerosol delivery for pediatric patients receiving mechanical ventilation, there is little research on aerosol delivery during pediatric NIV. ${ }^{58-63}$ Fauroux et al ${ }^{58}$ performed an in vitro/in vivo study evaluating the effect of pressure support on aerosol delivery/lung deposition of 2 breath-actuated nebulizers. The in vitro study did not show any differences in aerosol delivery. Conversely, the in vivo part showed that the use of pressure support increased deposition efficacy from 11.5 to $15.3 \%$. Interestingly enough, neither regional deposition pattern, nor homogeneity of distribution changed.

White et $\mathrm{al}^{59}$ reported data on an in vitro model of a spontaneously breathing child receiving NIV with a V60 ventilator (Philips Respironics, Murrysville, Pennsylvania). The model comprised a tidal volume of $180 \mathrm{~mL}$ and a breathing frequency of 30 breaths/min. A pediatric resuscitation mannequin connected to an ETT with ID of $5.5 \mathrm{~mm}$ was used. The ventilator was set on $16 / 8 \mathrm{~cm} \mathrm{H}_{2} \mathrm{O}$, rise time setting 2 and autotrack trigger. A small oronasal mask (AF531, Philips Respironics, Murrysville, Pennsylvania) was used. The authors compared albuterol delivery using a vibrating mesh nebulizer placed in 3 different positions: (1) dry side of the humidifier, (2) right before the mask and the leak, and (3) integrated into the mask after the leak. The authors reported approximately 4,5 , and $11 \%$ delivery efficiency for positions 1,2 , and 3 , respectively.

More recently, Velasco et al compared aerosol delivery in an anatomically correct in vitro model of a spontaneously breathing child receiving NIV. ${ }^{60}$ The authors used a
Servo-i ventilator operated on bi-level S/T mode with pressures $15 / 5 \mathrm{~cm} \mathrm{H}_{2} \mathrm{O}$, inspiratory time $1 \mathrm{~s}$, and backup frequency 15 breaths $/ \mathrm{min}$. The breathing simulator was set to deliver a tidal volume of $200 \mathrm{~mL}$ at a breathing frequency of $20 \mathrm{breaths} / \mathrm{min}$ and an inspiratory time of $0.75 \mathrm{~s}$. The authors used an adult size heated-wire circuit (Evaqua, Fisher \& Paykel Healthcare, Auckland, New Zealand), and a vibrating mesh nebulizer was placed either on the dry side of the humidifier (Fisher \& Paykel, Auckland, New Zealand), between the Y-piece and the end of the inspiratory limb, or between the Y-piece and the mask. The authors reported a $13.3,18$, and $17.6 \%$ delivery efficiency when the nebulizer was placed at the humidifier, before the Y-piece, and between the Y-piece and the mask, respectively. The same authors also looked at a continuousoutput jet nebulizer (Hudson Optineb, Teleflex Medical, Research Triangle Park, North Carolina), operated at 6 $\mathrm{L} / \mathrm{min}$, placed at the dry side of the humidifier, and between the inspiratory limb and the Y-piece (unpublished data). They found similar delivery efficiency between both positions (3.8 and 3.5\%, respectively). The authors also replicated the study with different bi-level ventilator settings (20/5 $\left.\mathrm{cm} \mathrm{H}_{2} \mathrm{O}\right)$ (unpublished data). Delivery efficiency was unchanged except for a reduction for the continuous-output nebulizer placed at the ventilator. These findings are different from those obtained in adult models of NIV, where the highest inspiratory pressure was associated with the highest aerosol delivery. ${ }^{61}$

Data originating in a study using an adult model showed that actuation of a pMDI, attached to a spacer, during exhalation resulted in a significant decrease of the delivered dose. ${ }^{62}$ They also found that the position of the leak (mask vs circuit) did not affect aerosol delivery. In vitro testing with $\mathrm{pMDI} /$ adapter, $\mathrm{pMDI} / \mathrm{spacer}$, and soft mist inhaler with 2 different adapters placed between the inspiratory limb and the Y-piece of a dual-limb circuit with a previously reported pediatric model showed a delivery efficiency of $1.3,4.1,8.9$, and $14 \%$, respectively (unpublished data). ${ }^{60}$

Lin et al evaluated aerosol delivery efficiency of a vibrating mesh nebulizer (Solo, Aerogen, Galway, Ireland) placed on the dry side of a heated-flow system (MR410, Fisher \& Paykel, Auckland, New Zealand) connected to a face mask using a model of a spontaneously breathing child. ${ }^{63}$ The authors tested a front-loaded and bottomloaded mask with flows of 3, 6, and $12 \mathrm{~L} / \mathrm{min}$. They used a resuscitation mannequin connected to a breathing simulator delivering 2 different breathing patterns (tidal volume $=100$ and $250 \mathrm{~mL}$, breathing frequency $=30$ and 20 breaths/min, and I:E of 1:2). The authors also measured particle size of the aerosol using cascade impaction. They reported a reduction in MMAD of the aerosol exiting the heated-wire circuit $(2.8,3.3$, and $2.8 \mu \mathrm{m}$ for the 3,6 , and $12 \mathrm{~L} / \mathrm{min}$, respectively) when compared with the device 


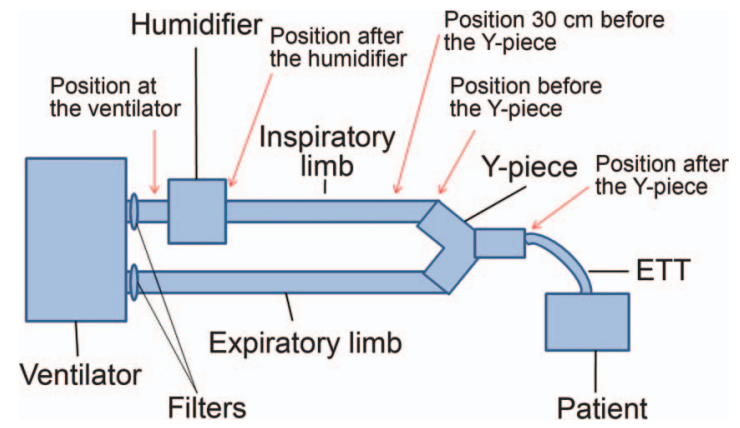

Fig. 3. Diagram of a dual-limb ventilator circuit used during invasive ventilation. From Reference 55, with permission.

alone $(4 \mu \mathrm{m})$. The authors reported that the delivered dose was lower for the $12 \mathrm{~L} / \mathrm{min}$ flow than for the 3 and $6 \mathrm{~L} / \mathrm{min}$ flow for both breathing patterns. They also reported that the breathing pattern with the largest tidal volume resulted in higher delivered dose. The average delivered dose was 5.6, 5.2, and $3 \%$ (tidal volume $=100 \mathrm{~mL}$ ) and 7.7, 7.0, and $4.6 \%$ (tidal volume $=250 \mathrm{~mL}$ ) for the 3,6 , and $12 \mathrm{~L} / \mathrm{min}$, respectively.

In summary, these studies show that: (1) placing a vibrating mesh nebulizer in the mask after the leak improved aerosol delivery when using a single-limb circuit, (2) placing a vibrating mesh nebulizer between the Y-piece and the unvented mask improved aerosol delivery when using a double-limb circuit; (3) the vibrating mesh nebulizer is 3.5-5-fold more efficient that the jet nebulizer in a doublelimb circuit; (4) high flows with a heated flow attached to the mask result in decreased aerosol delivery, and (5) pMDI with a spacer should be actuated during inhalation.

\section{Delivery Device Selection for Mechanically Ventilated Pediatric Patients}

Aerosol delivery during mechanical ventilation is a complex process that could be affected by several variables. The data for adults are extensive and include both in vivo and in vitro data. ${ }^{64}$ In contrast, pediatric (non neonatal) data are limited and mostly derived from in vitro studies. Aerosols are mostly delivered inline, thus avoiding derecruitment and also decreasing the risk for development of ventilator-associated pneumonia that results from disconnecting the circuit. Most centers utilize heated-wire circuits, which limits the alternatives for placement of devices (Fig. 3). ${ }^{55}$ Garner et al ${ }^{65}$ reported similar clinical effects and albuterol concentrations in ventilated subjects receiving albuterol therapy via pMDI/spacer (between Y-piece and ETT) and a jet nebulizer placed in the inspiratory limb (10-20 $\mathrm{cm}$ before the Y-piece).

Ferrari et al ${ }^{66}$ reported that an ultrasonic nebulizer placed $40 \mathrm{~cm}$ before the Y-piece had delivery efficiency similar to that of a vibrating mesh nebulizer placed $15 \mathrm{~cm}$ before the Y-piece in a porcine model of mechanical ventilation. Berlinski et al ${ }^{67}$ compared the delivery efficiency of albuterol in an ex vivo porcine model of mechanical ventilation (tidal volume $65 \mathrm{~mL}$, neonatal circuit). They reported delivery efficiency for the pMDI with an adapter (2\%) and spacer (7.4\%) placed before the Y-piece and with a jet (1.9\%), vibrating mesh (17.5\%), and ultrasonic nebulizer (19.6\%) placed at the ventilator, respectively.

Metered-dose inhalers are usually placed either before the Y-piece (inspiratory limb) or after the Y-piece (before the ETT). The latter has the disadvantage of adding deadspace to the system and potentially resulting in the therapist moving the ETT. The canister of the pMDI has to be removed from the plastic actuator and connected to spacers/VHC or an adapter. This could result in a decreased drug output. $68-70$ Several in vitro studies have reported that the adapter performs poorly, and more recently a pediatric animal model showed a 4-fold difference when compared with the VHC. ${ }^{67}$ The spacers/VHC made of nonelectrostatic material are more efficient that those that are not.

Diot et $\mathrm{al}^{71}$ using an adult model of mechanical ventilation reported that actuation of the pMDI during exhalation resulted in a 35 and $86 \%$ reduction of drug output for the spacer and adapter, respectively. Garner et al ${ }^{68,72}$ reported that the presence of humidity in the ventilator circuit of a pediatric model resulted in 30-60\% increased drug delivery (albuterol chlorofluorocarbon). The same group reported that the use of a helium-oxygen combination increased albuterol delivery by $65 \% .73,74$ Similarly to what is reported for tracheostomies, the ID of the ETT affects drug delivery.

Garner et al ${ }^{68,72}$ reported a $40-60 \%$ reduction in drug delivery when the ID of the ETT was reduced from 6 to $4 \mathrm{~mm}$. It is not surprising that Mitchell et al ${ }^{75}$ reported that the use of a smaller size formulation of beclomethasone (MMAD $1.2 \mu \mathrm{m}$ ) resulted in higher drug delivery than using a larger size formulation (MMAD $4.5 \mu \mathrm{m}$ ) in an adult model of mechanical ventilation (ETT ID $8 \mathrm{~mm}$ ). The same authors showed that MMAD of an hydrofluoroalkane formulation increased from 1.2 to $2.8 \mu \mathrm{m}$ when humidity was changed from 54 to $100 \%$. In vitro and in vivo adult data suggest that neither ventilator mode nor flow pattern nor use of end-expiratory pause affects drug delivery/clinical response. ${ }^{76,77}$

Several variables can affect delivery of aerosols generated by nebulizers in pediatric models of mechanical ventilation. These variables include type of aerosol generator, position in a ventilator circuit, mode of operation, size of ventilator circuit, type of ventilator, ID of the ETT, particle size of the aerosol, presence of humidity, and presence of bias flow. Practitioners need to adjust the ventilator setting (eg, tidal volume) when using a jet nebulizer to avoid the risk of barotrauma and volutrauma. ${ }^{78} \mathrm{~A}$ decrease 
in drug delivery has been reported when the gas flow powering the jet nebulizers is increased. ${ }^{79}$ Studies in adult models report a significant decrease $(60 \%)$ in drug delivery when humidity is present in the ventilator circuit. ${ }^{80}$

Di Paolo et al ${ }^{81}$ compared albuterol delivery of 6 nebulizers placed before the Y-piece and operated in a pediatric model of mechanical ventilation (tidal volume $100 \mathrm{~mL}$, breathing frequency 25/min, I:E 1:2, ETT ID $4 \mathrm{~mm}$, and circuit ID $15 \mathrm{~mm}$ ) during inspiration, expiration, continuous, and continuous with external gas source. In the first 3 scenarios the nebulizer was powered by the ventilator. Humidification was interrupted during nebulization. They reported that drug delivery was 1.9, 6.5, 4.0, and 4.2\% during inspiration, expiration, continuous, and continuous with external gas source, respectively.

Ari et al ${ }^{82}$ compared albuterol delivery by a continuousoutput jet nebulizer and a vibrating mesh nebulizer in a pediatric model of mechanical ventilation (tidal volume $100 \mathrm{~mL}$, breathing frequency 20/min, I:E 1:2, ETT ID $5 \mathrm{~mm}$, and circuit ID $15 \mathrm{~mm}$ ). Both nebulizers were placed on the dry side of the humidifier, and the vibrating mesh nebulizer was placed right before the Y-piece, whereas the jet nebulizer was placed $40 \mathrm{~cm}$ before the Y-piece. The ventilator was operated with a bias flow of 2 and $5 \mathrm{~L} / \mathrm{min}$. The vibrating mesh nebulizer (8.4-13.6\%) was 2-3-fold more efficient than the jet nebulizer (3.8-5.2\%). They also reported that bias flow did not affect drug delivery and that the position of the nebulizer did not affect it either.

Berlinski and Willis ${ }^{83}$ compared albuterol delivery by a jet nebulizer and an intrapulmonary percussive ventilator in a pediatric model of mechanical ventilation (tidal volume 100 and $200 \mathrm{~mL}$, breathing frequency 20/min, I:E 1:3, ETT ID $5.5 \mathrm{~mm}$, and circuit ID $22 \mathrm{~mm}$ ). The authors reported that the jet nebulizer (3.6-4.7\%) performed similarly at different locations and with different tidal volumes. However, the intrapulmonary percussive ventilator was less efficient at the humidifier than at the Y-piece (1.1-1.8\% vs $3.2-4.1 \%)$.

Using the same model, Berlinski and Willis ${ }^{84}$ compared albuterol delivery by 2 jet nebulizers, a vibrating mesh and an ultrasonic nebulizer placed at the ventilator, after the humidifier, $30 \mathrm{~cm}$ before the Y-piece, and between the inspiratory line and the Y-piece. They also tested different albuterol concentrations and different loading volumes. The authors reported that jet nebulizers averaged 4.2, 4.7, 4.3 , and $3.7 \%$ delivery efficiency when placed at the ventilator, after the humidifier, $30 \mathrm{~cm}$ before the Y-piece, and between the inspiratory line and the Y-piece, respectively. The ultrasonic nebulizer showed a delivery efficiency of $12.8,17.1,10.5$, and $8.7 \%$ for similar positions. The vibrating mesh nebulizer was the most efficient with 28.5 , $33.3,10.3$, and $8.7 \%$ for similar positions. The authors also reported that higher volume load at similar drug load- ing dose, and higher loading dose at similar loading volume resulted in a higher amount of delivered drug (Table 3).

Sidler-Moix et al ${ }^{85}$ compared albuterol delivery of jet, ultrasonic, and vibrating mesh nebulizers operated in a pediatric model of mechanical ventilation (tidal volume $100 \mathrm{~mL}$, breathing frequency 25/min, I:E 1:2, ETT ID $4 \mathrm{~mm}$, and circuit ID $22 \mathrm{~mm}$ ) during inspiration, expiration, and continuous operation. The authors reported that the jet nebulizer delivered $2.8,6.4$, and $3.7 \%$ during inspiration, expiration, and continuous operation, respectively. The ultrasonic nebulizer delivered 10.5 and $5.1 \%$ during inspiration and continuous operation mode, respectively. Finally, the vibrating mesh nebulizer delivered 5.4, 8, and $13.3 \%$ during inspiration, expiration, and continuous operation, respectively.

Wan et al ${ }^{86}$ compared albuterol delivery of a jet nebulizer placed between the ventilator and the humidifier operated in a pediatric model of mechanical ventilation (tidal volume $160 \mathrm{~mL}$, breathing frequency $25 / \mathrm{min}$, I:E 1:2, ETT ID $5 \mathrm{~mm}$, and circuit ID $15 \mathrm{~mm}$ ) during inspiration, expiration, and continuous operation. All modes resulted in similar delivery efficiency $(6.3 \%)$, but continuous and expiratory mode showed half of inspiratory mode nebulization time.

All of the comparisons among timing of delivery were done using a mechanical ventilator that powered the devices and provided the synchronization. It is worth mentioning that poor performance of jet nebulizers powered by different ventilators has been reported. ${ }^{79}$

Berlinski and Willis ${ }^{87}$ compared albuterol delivery in a pediatric model of mechanical ventilation (tidal volume 100, 150,200 , and $300 \mathrm{~mL}$; breathing frequency 20 breaths $/ \mathrm{min}$; I:E 1:3; ETT ID $5.5 \mathrm{~mm}$; and circuit ID $22 \mathrm{~mm}$ ). They studied a jet nebulizer and a vibrating mesh nebulizer placed at the ventilator and between the inspiratory limb and the Y-piece. The authors found no difference among tidal volumes for the jet nebulizer (8.7-9.9\%) and the vibrating mesh nebulizer $(9.5-14.7 \%)$ placed at the ventilator and jet nebulizer placed at the Y-piece (3.6-4.1\%). However, the vibrating mesh placed before the Y-piece had a higher lung dose with the lowest tidal volume than with the others (7.4\% vs $3.2-3.7 \%)$.

Similarly to what has been reported for pMDIs, the use of ETTs of smaller ID decreases drug delivery. ${ }^{88,89}$ Ahrens et $\mathrm{al}^{88}$ reported a $60 \%$ reduction in drug output when the ID of the ETT was reduced from 6 to $3 \mathrm{~mm}$. The authors also reported a significant reduction in MMAD for aerosols with MMAD of $3.6 \mu \mathrm{m}$ but not for those of submicronic size.

More recently, Berlinski and Kumaran ${ }^{89}$ evaluated particle size and output of aerosols generated by vibrating mesh and jet nebulizers placed in a neonatal circuit and exiting pediatric ETTs. They reported that for the jet and vibrating nebulizer, there was no difference in output between ETTs with ID 3.5 and $5 \mathrm{~mm}$ and that drug output 
Table 3. Evaluation of the Effect of Changes in Loading Volume/Nominal Dose on Lung Dose

\begin{tabular}{|c|c|c|c|c|}
\hline \multirow{2}{*}{ Nebulizer } & \multirow{2}{*}{$\begin{array}{c}\text { Albuterol } \\
\text { Solution }(\mathrm{mg} / \mathrm{mL})\end{array}$} & \multicolumn{3}{|c|}{ Lung Dose $(\mu \mathrm{g})$} \\
\hline & & Ventilator & Humidifier & Y-piece \\
\hline \multirow[t]{5}{*}{ Jet Hudson } & $2.5 / 3$ & $135.4 \pm 15.8$ & $117.5 \pm 19.4$ & $51 \pm 2.9$ \\
\hline & $2.5 / 4$ & $191.8 \pm 34.1^{*}$ & $135.5 \pm 7.4^{*}$ & $63.3 \pm 13.6$ \\
\hline & $7.5 / 4 \dagger$ & $497.6 \pm 76.7$ & $527.8 \pm 30.9$ & $129.3 \pm 22.2$ \\
\hline & $2.5 / 3.5$ & $246.8 \pm 29.7$ & $154.7 \pm 19.7$ & $66.8 \pm 13.2$ \\
\hline & $5 / 3.5 \ddagger$ & $330.6 \pm 39.3$ & $270.2 \pm 47.8$ & $137.5 \pm 13.6$ \\
\hline \multirow[t]{5}{*}{ Jet Salter } & $2.5 / 3$ & $76.4 \pm 21.5$ & $115.6 \pm 21.3$ & $70.9 \pm 9.6$ \\
\hline & $2.5 / 4$ & $127.9 \pm 19.6^{*}$ & $103.9 \pm 21.2$ & $49.6 \pm 7.8$ \\
\hline & $7.5 / 4$ & $270.2 \pm 54.5 \S$ & $253.7 \pm 35.7 \S$ & $93.6 \pm 40.8$ \\
\hline & $2.5 / 3.5$ & $145.8 \pm 52.8$ & $117.6 \pm 28.1$ & $50.3 \pm 9$ \\
\hline & $5 / 3.5 \ddagger$ & $226.9 \pm 64.1$ & $185.6 \pm 25.4$ & $111.4 \pm 10.7$ \\
\hline \multirow[t]{5}{*}{ Ultrasonic } & $2.5 / 3$ & $319.5 \pm 38$ & $428.7 \pm 36.7$ & $216.4 \pm 16.3$ \\
\hline & $2.5 / 4$ & $431.1 \pm 136.6$ & $515.3 \pm 49.3^{*}$ & $144.2 \pm 30.1$ \\
\hline & $7.5 / 4 \dagger$ & $1,048.9 \pm 346.4$ & $1,820 \pm 56.6$ & $316.9 \pm 30.9$ \\
\hline & $2.5 / 3.5$ & $401.1 \pm 92.8$ & $429.4 \pm 135.1$ & $156.3 \pm 8.5$ \\
\hline & $5 / 3.5$ & $519.6 \pm 152.2$ & $712 \pm 163.2 \|$ & $278.3 \pm 30.5 \|$ \\
\hline \multirow[t]{5}{*}{ Vibrating mesh } & $2.5 / 3$ & $711.3 \pm 214.8$ & $831.6 \pm 90.4$ & $216.6 \pm 62.8$ \\
\hline & $2.5 / 4$ & $736 \pm 246.5$ & $740.8 \pm 251.7$ & $208.3 \pm 70.9$ \\
\hline & $7.5 / 4 \dagger$ & $2,090 \pm 317.6$ & $1,872.6 \pm 533.8$ & $1,046 \pm 247.8$ \\
\hline & $2.5 / 3.5$ & $834.5 \pm 239.4$ & $897.4 \pm 252.3$ & $208.3 \pm 44.4$ \\
\hline & $5 / 3.5 \$$ & $1,618.4 \pm 320.3$ & $1,528.2 \pm 277.6$ & $417.2 \pm 60$ \\
\hline \multicolumn{5}{|c|}{$\begin{array}{l}\text { Lung dose is expressed in } \mu \mathrm{g} \text { as mean } \pm \mathrm{SD} \text {. } \\
\text { * Drug output for } 2.5 \mathrm{mg} / 4 \mathrm{~mL} \text { was higher than for } 2.5 \mathrm{mg} / 3 \mathrm{~mL} \text { at this position. ( } \mathrm{F}) \\
\dagger \text { Drug output for } 7.5 \mathrm{mg} / 4 \mathrm{~mL} \text { was higher than for } 2.5 \mathrm{mg} / 4 \mathrm{~mL} \text { at all positions. } \\
\text { † Drug output for } 5 \mathrm{mg} / 3.5 \mathrm{~mL} \text { was higher than for } 2.5 \mathrm{mg} / 3.5 \mathrm{~mL} \text { at all positions. } \\
\S \text { Drug output for } 5 \mathrm{mg} / 3.5 \mathrm{~mL} \text { was higher than for } 2.5 \mathrm{mg} / 3.5 \mathrm{~mL} \text { at this position. } \\
\| \text { Drug output for } 5 \mathrm{mg} / 3.5 \mathrm{~mL} \text { was higher than for } 2.5 \mathrm{mg} / 3.5 \mathrm{~mL} \text { at this position. }\end{array}$} \\
\hline
\end{tabular}

before the Y-piece was 2-fold higher than when placed at the dry side of the humidifier. The vibrating mesh nebulizer was twice as efficient as the jet nebulizer. The aerosols generated at the Y-piece had a lower percentage of aerosols in the respirable range $(<5 \mu \mathrm{m})$. The authors also found that although a decrease in MMAD was noted when decreasing from ETT with ID of 5 to $3.5 \mathrm{~mm}$, the phenomenon was more marked at the Y-piece (28.5-58.9\%) than at dry side of the humidifier (13.2-20.1\%).

Fang et $\mathrm{al}^{90}$ studied albuterol delivery in a pediatric model of high frequency oscillatory ventilation (ETT ID $5.5 \mathrm{~mm}, \mathrm{I}: \mathrm{E} 1: 2$, bias flow $25 \mathrm{~L} / \mathrm{min}$, mean airway pressure $18 \mathrm{~cm} \mathrm{H}_{2} \mathrm{O}$, and frequency $8 \mathrm{~Hz}$ ). They placed a jet and a vibrating mesh nebulizer before the humidifier and before the ETT. Delivery was negligible at the humidifier for any device $(0-0.3 \%)$, whereas it reached 4.3 and 17.4 for the jet and vibrating mesh nebulizers placed before the ETT.

Utilizing a concept similar to one discussed above, Longest and $\operatorname{Tian}^{91}$ reported a significant improvement in lung delivery during mechanical ventilation by streamlining the connectors and using an excipient-enhanced growth technique. The dry powder formulation had a starting MMAD of $0.9 \mu \mathrm{m}$. The authors report that these techniques result in 68 and $96 \%$ alveolar and total lung deposition, respectively. These novel approaches have not yet been validated in in vivo models.

Optimization of drug delivery during pediatric mechanical ventilation should include several strategies. A spacer/VHC should be used instead of an adapter when pMDIs are used, and actuation should occur at the beginning of inhalation. Best placement of a nebulizer depends on the circuit size. When adult-type circuits are used, placing the nebulizer on the dry side optimizes delivery. The opposite occurs when small circuits are used. Vibrating mesh nebulizers are more efficient than jet nebulizers and do not interfere with the ventilator but are more expensive. Increasing the tidal volume during nebulization does not increase aerosol delivery. A major challenge that practitioners encounter when trying to decide which device to use is that the optimal dose for many drugs delivered to ventilated pediatric patients is unknown.

\section{Summary}

Both nebulizers and pMDI/VHC are effective in delivering bronchodilators to children experiencing acute bron- 


\section{Pediatric Aerosol Therapy}

choconstriction. Aerosol delivery through HFNC is significantly affected by gas flow rate. Lack of clinical response could be due to low lung delivery. Aerosol delivery through pediatric tracheostomy tubes is impaired by small ID, breathing pattern with low tidal volume, and use of assisted technique. Aerosol delivery during NIV with single limb circuits increases when placing the device closer to the mask and distal to the circuit leak. Placing the nebulizer before the Y-piece increases aerosol delivery in a double limb ventilator circuit. Finally, vibrating mesh nebulizers are more efficient that continuous output jet nebulizers. Aerosol delivery during invasive mechanical ventilation can be enhanced by placing the nebulizer on the dry side of the humidifier with adult circuits and before the Y-piece with neonatal circuits. More animal and human studies are necessary to enhance our understanding on how to deliver aerosols to pediatric patients in these scenarios.

\section{REFERENCES}

1. National Asthma Education and Prevention Program. National Heart, Lung, and Blood Institute, National Institutes of Health. Expert panel report 3: guidelines for the diagnosis and management of asthma. NIH publication No 08-4051, Bethesda, MD: National Institutes of Health; 2007. http://www.nhlbi.nih.gov/health-pro/guidelines/ current/asthma-guidelines. Accessed March 10, 2017.

2. Abadesso C, Nunes P, Silvestre C, Matias E, Loureiro H, Almeida H. Non-invasive ventilation in acute respiratory failure in children. Pediatr Rep 2012;4(2):e16.

3. ten Brink F, Duke T, Evans J. High-flow nasal prong oxygen therapy or nasopharyngeal continuous positive airway pressure for children with moderate-to-severe respiratory distress? Pediatr Crit Care Med 2013;14(7):e326-e331.

4. Willis LD, Berlinski A. Survey of aerosol delivery techniques to spontaneously breathing tracheostomized children. Respir Care 2012; 57(8):1234-1241.

5. DiBlasi RM. Clinical controversies in aerosol therapy for infants and children. Respir Care 2015;60(6):894-914; discussion 914-916.

6. 't Jong GW, Eland IA, Sturkenboom MCJM, van den Anker JN, Stricker BHC. Unlicensed and off-label prescription of respiratory drugs to children. Eur Respir J 2004;23(2):310-313.

7. Amirav I, Newhouse MT, Minocchieri S, Castro-Rodriguez JA, Schüepp KG. Factors that affect the efficacy of inhaled corticosteroids for infants and young children. J Allergy Clin Immunol 2010; 125(6):1206-1211.

8. Hanania NA, Wittman, R, Kesten, S, Chapman, KR. Medical personnel's knowledge of and ability to use inhaling devices: metereddose inhalers, spacing chambers, and breath-actuated dry powder inhalers. Chest 1994;105(1):111-116.

9. Giner J, Roura P, Hernández C, Torrejón M, Peiró M, Fernández MJ, et al. Knowledge and attitudes of nurses in spain about inhaled therapy: results of a national survey. J Aerosol Med Pulm Drug Deliv 2016;29(1):86-93. doi: 10.1089/jamp.2014.1198.

10. Castro-Rodriguez JA, Rodrigo GJ. Beta-agonists through metered-dose inhaler with valved holding chamber versus nebulizer for acute exacerbation of wheezing or asthma in children under 5 years of age: a systematic review with meta-analysis. J Pediatr 2004;145(2):172-177.

11. Cates CJ, Welsh EJ, Rowe BH. Holding chambers (spacers) versus nebulisers for beta-agonist treatment of acute asthma. Cochrane Database Syst Rev 2013;(9):CD000052.
12. Salyer JW, DiBlasi RM, Crotwell DN, Cowan CA, Carter ER. The conversion to metered-dose inhaler with valved holding chamber to administer inhaled albuterol: a pediatric hospital experience. Respir Care 2008;53(3):338-345.

13. ProAirR HFA Package Insert. Highlights of prescribing information. Horsham, Pennsylvania: Teva Respiratory; Revised June 2016.

14. ProventilR HFA Package Insert. Prescribing information. Kenilworth, New Jersey: Schering-Plough Corporation; Revised December 2014.

15. VentolinR HFA Package Insert. Highlights of prescribing information. Brentford, United Kingdom: GlaxoSmithKline; Revised December 2014.

16. Berlinski A, Pennington D. Effect of interval between actuations of albuterol HFA inhalers on their aerosol characteristics (abstract). Eur Respir J 2016;48(Suppl 60):A3363.

17. Chua HL, Collis GG, Newbury AM, Chan K, Bower GD, Sly PD, Le Souef PN. The influence of age on aerosol deposition in children with cystic fibrosis. Eur Respir J 1994;7(12):2185-2191.

18. Amirav I, Luder A, Chleechel A, Newhouse MT, Gorenberg M. Lung aerosol deposition in suckling infants. Arch Dis Child 2012; 97(6):497-501.

19. Mallol J, Rattray S, Walker G, Cook D, Robertson CF. Aerosol deposition in infants with cystic fibrosis. Pediatr Pulmonol 1996; 21(5):276-281.

20. Schüepp KG, Devadson S, Roller C, Wildhaber JH. A complementary combination of delivery device and drug formulation for inhalation therapy in preschool children. Swiss Med Wkly 2004;134(1314):198-200.

21. Amirav I, Borojeni AA, Halamish A, Newhouse MT, Golshahi L. Nasal versus oral aerosol delivery to the "lungs" in infants and toddlers. Pediatr Pulmonol 2015;50(3):276-283. doi: 10.1002/ppul. 22999.

22. Xi J, Si X, Kim JW, Berlinski A. Simulation of airflow and aerosol deposition in the nasal cavity of a 5-year-old child. J Aerosol Sci 2011;42(3):156-173.

23. El Taoum KK, Xi J, Kim J, Berlinski A. In-vitro evaluation of nebulized aerosols delivered via nasal route. Respir Care 2015;60(7): 1015-1025.

24. Berlinski A, Xi J. Characterization of nebulized aerosols using a next generation impactor and an anatomically correct pediatric airway model. Respir Drug Deliv 2014;3:637-640.

25. Berlinski A, and Hayden JB. Optimization of a procedure used to measure aerosol characteristics of nebulized solutions using a cooled next generation impactor. J Aerosol Med Pulm Drug Deliv 2010; 23(6):397-404.

26. Cooper B, Berlinski A. Albuterol delivery via facial and tracheostomy route in a model of a spontaneously breathing child. Respir Care 2015;60(12):1749-1758.

27. Janssens HM, de Jongste JC, Fokkens WJ, Robben SG, Wouters K, Tiddens HA. The Sophia Anatomical Infant Nose-Throat (Saint) model: a valuable tool to study aerosol deposition in infants. J Aerosol Med 2001;14(4):433-441.

28. Janssens HM, De Jongste JC, Hop WC, Tiddens HA. Extra-fine particles improve lung delivery of inhaled steroids in infants: a study in an upper airway model. Chest 2003;123(6):2083-2088.

29. Bhashyam AR, Wolf MT, Marcinkowski AL, Saville A, Thomas K, Carcillo JA, Corcoran TE. Aerosol delivery through nasal cannulas: an in vitro study. J Aerosol Med Pulm Drug Deliv 2008;21(2):181-188.

30. Longest PW, Golshahi L, Hindle M. Improving pharmaceutical aerosol delivery during noninvasive ventilation: effects of streamlined components. Ann Biomed Eng 2013;41(6):1217-1232.

31. Ari A, Harwood R, Sheard M, Dailey P, Fink JB. In vitro comparison of heliox and oxygen in aerosol delivery using pediatric high flow nasal cannula. Pediatr Pulmonol 2011;46(8):795-801. 


\section{Pediatric Aerosol Therapy}

32. Perry SA, Kesser KC, Geller DE, Selhorst DM, Rendle JK, Hertzog $\mathrm{JH}$. Influences of cannula size and flow rate on aerosol drug delivery through the Vapotherm humidified high-flow nasal cannula system. Pediatr Crit Care Med 2013;14(5):e250-e256.

33. Réminiac F, Vecellio L, Heuzé-Vourc'h N, Petitcollin A, Respaud R, Cabrera M, et al. Aerosol therapy in adults receiving high flow nasal cannula oxygen therapy. J Aerosol Med Pulm Drug Deliv 2016; 29(2):134-141.

34. Réminiac F, Vecellio L, Loughlin RM, Le Pennec D, Cabrera M, Vourc'h NH, et al. Nasal high flow nebulization in infants and toddlers: An in vitro and in vivo scintigraphic study. Pediatr Pulmonol 2017;52(3):337-344.

35. O'Brien KC, Newth CJL, Leung K, and Coates A. Epinephrine delivery using a humidified high flow oxygen delivery system (abstract). Am J Respir Crit Care Med 2007;175:A195.

36. Leung K, Newth CJ, Hotz JC, O'Brien KC, Fink JB, Coates AL. Delivery of epinephrine in the vapor phase for the treatment of croup. Pediatr Crit Care Med 2016;17(4):e177-e181.

37. Farney KD, Kuehne BT, Gibson LA, Nelin LD, Shepherd EG. In vitro evaluation of radio-labeled aerosol delivery via a variable-flow infant CPAP system. Respir Care 2014;59(3):340-344.

38. Boucher P, Boucher R, Button BM, Johnson MR, Fink JB, Hickey AJ, et al. Aerosol delivery systems, compositions and methods. United States Patent 20140109899 A1. http://www.google.com/patents/ US20140109899. Accessed March 10, 2017.

39. Morgan SE, Mosakowski S, Solano P, Hall JB, Tung A. High-flow nasal cannula and aerosolized $\beta$ agonists for rescue therapy in children with bronchiolitis: a case series. Respir Care 2015;60(9):e161e165.

40. Longest PW, Golshahi L, Behara SR, Tian G, Farkas DR, Hindle M. Efficient nose-to-lung (N2L) aerosol delivery with a dry powder inhaler. J Aerosol Med Pulm Drug Deliv 2015;28(3):189-201.

41. Golshahi L, Tian G, Azimi M, Son YJ, Walenga R, Longest PW, Hindle M. The use of condensational growth methods for efficient drug delivery to the lungs during noninvasive ventilation high flow therapy. Pharm Res 2013;30(11):2917-2930.

42. Trachsel D, Hammer J. Indications for tracheostomy in children. Paediatr Respir Rev 2006;7(3):162-168.

43. Baran D, Dachy A, Klastersky J. Concentration of gentamicin in bronchial secretions of children with cystic fibrosis of tracheostomy (Comparison between the intramuscular route, the endotracheal instillation and aerosolization). Int J Clin Pharmacol Biopharm 1975;12(3):336341.

44. Lewis JF, McCaig L. Aerosolized versus instilled exogenous surfactant in a nonuniform pattern of lung injury. Am Rev Respir Dis 1993;148(5):1187-1193.

45. Berlinski A, Chavez A. Albuterol delivery via metered dose inhaler in a spontaneously breathing pediatric tracheostomy model. Pediatr Pulmonol 2013;48(10):1026-1034.

46. Berlinski A. Nebulized albuterol delivery in a model of spontaneously breathing children with tracheostomy. Respir Care 2013;58(12): 2076-2086.

47. Alhamad BR, Fink JB, Harwood RJ, Sheard MM, Ari A. Effect of aerosol devices and administration techniques on drug delivery in a simulated spontaneously breathing pediatric tracheostomy model. Respir Care 2015;60(7):1026-1032.

48. Berlinski A, Cooper B. Oronasal and tracheostomy delivery of soft mist and pressurized metered-dose inhalers with valved holding chamber. Respir Care 2016;61(7):913-919.

49. Piccuito CM, Hess DR. Albuterol delivery via tracheostomy tube. Respir Care 2005;50(8):1071-1076.

50. Amirav I, Newhouse MT. Aerosol therapy in tracheotomized children: time for guidelines! Respir Care 2012;57(8):1350.
51. Sherman JM, Davis S, Albamonte-Petrick S, Chatburn RL, Fitton C, Green C, et al. Care of the child with a chronic tracheostomy. This official statement of the American Thoracic Society was adopted by the ATS Board of Directors, July 1999. Am J Respir Crit Care Med 2000;161(1):297-308.

52. Ari A, Harwood RJ, Sheard MM, Fink JB. An in vitro evaluation of aerosol delivery through tracheostomy and endotracheal tubes using different interfaces. Respir Care 2012;57(7):1066-1070.

53. Lazner MR, Basu AP, Klonin H. Non-invasive ventilation for severe bronchiolitis: analysis and evidence. Pediatr Pulmonol 2012;47(9): 909-916.

54. Amaddeo A, Moreau J, Frapin A, Khirani S, Felix O, FernandezBolanos $\mathrm{M}$, et al. Long term continuous positive airway pressure (CPAP) and noninvasive ventilation (NIV) in children: initiation criteria in real life. Pediatr Pulmonol 2016;51(9):968-974.

55. Berlinski A. Inhaled drug delivery for children on long-term mechanical ventilation. In: Sterni LM and Carroll JL. Caring for the ventilator dependent child: a clinical guide, 1st edition. New York: Humana Press; 2016:217-239.

56. Brodie T, Adalat $\mathrm{S}$. Unilateral fixed dilated pupil in a well child. Arch Dis Child 2006;91(12):961.

57. Simonds AK, Hanak A, Chatwin M, Morrell M, Hall A, Parker KH, et al. Evaluation of droplet dispersion during noninvasive ventilation, oxygen therapy, nebuliser treatment and chest physiotherapy in clinical practice: implications for management of pandemic influenza and other airborne infections. Health Technol Assess 2010;14(46):131-172.

58. Fauroux B, Itti E, Pigeot J, Isabey D, Meignan M, Ferry G, et al. Optimization of aerosol deposition by pressure support in children with cystic fibrosis: an experimental and clinical study. Am J Respir Crit Care Med 2000;162(6):2265-2271.

59. White CC, Crotwell DN, Shen S, Salyer J, Yung D, Zheng J, DiBlasi RM. Bronchodilator delivery during simulated pediatric noninvasive ventilation. Respir Care 2013;58(9):1459-1466.

60. Velasco J, Berlinski A. Aerosol delivery in a pediatric model of non-invasive ventilation (abstract). Am J Respir Crit Care Med 2016;A2201.

61. Dai B, Kang J, Sun LF, Tan W, Zhao HW. Influence of exhalation valve and nebulizer position on albuterol delivery during noninvasive positive pressure ventilation. J Aerosol Med Pulm Drug Deliv 2014;27(2):125-132

62. Branconnier MP, Hess DR. Albuterol delivery during noninvasive ventilation. Respir Care 2005;50(12):1649-1653.

63. Lin HL, Harwood RJ, Fink JB, Goodfellow LT, Ari A. In vitro comparison of aerosol delivery using different face masks and flow rates with a high-flow humidity system. Respir Care 2015; 60(9):1215-1219.

64. Ari A, Fink JB, Dhand R. Inhalation therapy in patients receiving mechanical ventilation: an update. J Aerosol Med Pulm Drug Deliv 2012;25(6):319-332.

65. Garner SS, Wiest DB, Bradley JW, Habib DM. Two administration methods for inhaled salbutamol in intubated patients. Arch Dis Child 2002;87(1):49-53.

66. Ferrari F, Liu ZH, Lu Q, Becquemin MH, Louchahi K, Aymard G, et al. Comparison of lung tissue concentrations of nebulized ceftazidime in ventilated piglets: ultrasonic versus vibrating plate nebulizers. Intensive Care Med 2008;34(9):1718-1723.

67. Berlinski A, Holt S, Thurman T, and Heulitt M. Albuterol delivery during mechanical ventilation in an ex-vivo porcine model. J Aerosol Med Pulm Drug Deliv 2013;26(2):A57.

68. Garner SS, Wiest DB, Bradley JW. Albuterol delivery by metereddose inhaler with a pediatric mechanical ventilatory circuit model. Pharmacotherapy 1994;14(2):210-214. 
69. Wildhaber JH, Hayden MJ, Dore ND, Devadason SG, LeSouëf PN. Salbutamol delivery from a hydrofluoroalkane pressurized metereddose inhaler in pediatric ventilator circuits: an in vitro study. Chest 1998;113(1):186-191

70. Berlinski A, and Waldrep JC. Metering performance of several metered-dose inhalers with different spacers/holding chambers. J Aerosol Med 2001;14(4):427-432.

71. Diot P, Morra L, Smaldone GC. Albuterol delivery in a model of mechanical ventilation. Comparison of metered-dose inhaler and nebulizer efficiency. Am J Respir Crit Care Med 1995;152(4 Pt 1):1391-1394.

72. Garner SS, Wiest DB, Bradley JW. Albuterol delivery by metereddose inhaler in mechanically ventilated pediatric lung model. Crit Care Med 1996;24(5):870-874.

73. Habib DM, Garner SS, Brandeburg S. Effect of helium-oxygen on delivery of albuterol in a pediatric, volume-cycled, ventilated lung model. Pharmacotherapy 1999;19(2):143-149.

74. Garner SS, Wiest DB, Stevens CE, Habib DM. Effect of heliox on albuterol delivery by metered-dose inhaler in pediatric in vitro models of mechanical ventilation. Pharmacotherapy 2006;26(10):1396-1402.

75. Mitchell JP, Nagel MW, Wiersema KJ, Doyle CC, Migounov VA. The delivery of chlorofluorocarbon-propelled versus hydrofluoroalkane-propelled beclomethasone dipropionate aerosol to the mechanically ventilated patient: a laboratory study. Respir Care 2003;48(11): 1025-1032.

76. Mouloudi E, Katsanoulas K, Anastasaki M, Askitopoulou E, Georgopoulos D. Bronchodilator delivery by metered-dose inhaler in mechanically ventilated COPD patients: influence of end-inspiratory pause. Eur Respir J 1998;12(1):165-169.

77. Mouloudi E, Prinianakis G, Kondili E, Georgopoulos D. Bronchodilator delivery by metered-dose inhaler in mechanically ventilated COPD patients: influence of flow pattern. Eur Respir J 2000;16(2):263-268.

78. Hanhan U, Kissoon N, Payne M, Taylor C, Murphy S, DeNicola LK. Effects of in-line nebulization on preset ventilator variables. Respir Care 1993;38(5):474-478.

79. McPeck M, O'Riordan TG, and Smaldone GC. Choice of mechanical ventilator: influence on nebulizer performance. Respir Care 1993; 38(8):887-895.

80. Ari A, Areabi H, Fink JB. Evaluation of aerosol generator devices at 3 locations in humidified and non-humidified circuits during adult mechanical ventilation. Respir Care 2010;55(7):837-844.
81. Di Paolo ER, Pannatier A, Cotting J. In vitro evaluation of bronchodilator drug delivery by jet nebulization during pediatric mechanical ventilation. Pediatr Crit Care Med 2005;6(4):462-469.

82. Ari A, Atalay OT, Harwood R, Sheard MM, Aljamhan EA, Fink JB. Influence of nebulizer type, position, and bias flow on aerosol drug delivery in simulated pediatric and adult lung models during mechanical ventilation. Respir Care 2010;55(7):845-851.

83. Berlinski A, Willis JR. Albuterol delivery via intrapulmonary percussive ventilator and jet nebulizer in a pediatric ventilator model. Respir Care 2010;55(12):1699-1704.

84. Berlinski A, Willis JR. Albuterol delivery by 4 different nebulizers placed in 4 different positions in a pediatric ventilator in vitro model. Respir Care 2013;58(7):1124-1133.

85. Sidler-Moix AL, Dolci U, Berger-Gryllaki M, Pannatier A, Cotting J, Di Paolo ER. Albuterol delivery in an in vitro pediatric ventilator lung model: comparison of jet, ultrasonic, and mesh nebulizers. Pediatr Crit Care Med 2013;14(2):e98-e102.

86. Wan GH, Lin HL, Fink JB, Chen YH, Wang WJ, Chiu YC, et al. In vitro evaluation of aerosol delivery by different nebulization modes in pediatric and adult mechanical ventilators. Respir Care 2014; 59(10):1494-500.

87. Berlinski A, Willis JR. Effect of tidal volume and nebulizer type and position on albuterol delivery in a pediatric model of mechanical ventilation. Respir Care 2015;60(10):1424-1430.

88. Ahrens RC, Ries RA, Popendorf W, Wiese JA. The delivery of therapeutic aerosols through endotracheal tubes. Pediatr Pulmonol 1986;2(1):19-26

89. Berlinski A, Kumaran S. Particle size characterization of nebulized albuterol delivered by a vibrating mesh nebulizer through pediatric endotracheal tubes (abstract). Am J Respir Crit Care Med 2016;A2191.

90. Fang TP, Lin HL, Chiu SH, Wang SH, DiBlasi RM, Tsai YH, Fink JB. Aerosol delivery using jet nebulizer and vibrating mesh nebulizer during high frequency oscillatory ventilation: an in vitro comparison. J Aerosol Med Pulm Drug Deliv 2016;29(5):447453.

91. Longest PW, Tian G. Development of a new technique for the efficient delivery of aerosolized medications to infants on mechanical ventilation. Pharm Res 2015;32(1):321-336.

\section{Discussion}

Walsh: I have 3 questions, the first is MDIs. You mentioned about cost and a lot of places worked really hard to switch all their patients from small-volume nebulizers to MDIs years ago and to now be forced to go back because of the cost. How do we help people understand the exact cost? As you mentioned, it is very complicated, and a lot of places are allowed to use multi-use MDIs and others who are allowed to purchase institutional sized MDIs with smaller doses so they don't have to pay for the 120-puff dose, but it's a 50- or 60-dose. And some are allowed to relabel and send the 120-puff MDI home with them; if they have an asthma exacerbation, they can use it, and that helps save cost. But it's not universal across the country as far as what's acceptable practice, so I'd like your opinion on that.

Berlinski: I didn't say that it was fair or right, I'm saying it's the reality. We've spent 20 years trying to educate pediatricians and practitioners about the convenience and equivalence to nebulizers of using a pMDI with a valved holding chamber, especially in pediatrics. I think that the cost of the drugs has created a major issue with the transition from CFC [chlorofluorocarbon] to HFA [hydrofluoroalkane] propellants. There are some issues with some of what you mentioned as currently being used; multiple-patient use. I'm not sure that is an accepted practice by the Joint Commission, because my understanding is that each drug has to be labeled with the patient's name so you can't use the same device unless you relabel them. I think part of the challenge in calculating real cost of therapies is that we send patients home with the same pMDI that we used because the insurance or patient has been billed. I think we'll probably have to spend time explaining that the reimbursement model has changed and that we have so many dollars to spend for the treatment, especially in acute care. It's confusing because I tell my patients, "You should use a pMDI," but then when they get sick, I use a nebulizer. 
We went through this about 2 years ago when we re-worked our asthma protocol, and I was a firm supporter of using pMDIs in the emergency department, so we did a cost analysis, and when we added the cost of ipratropium bromide pMDI to the mix for a patient who is moderately ill, it became not sustainable. So it's a balancing act where institutions need to survive in order to deliver care and delivering care that is acceptable. But it creates a conflict between what we teach the patients as the best way of delivering aerosols and how we end up doing it ourselves in a different setting.

Panitch: Ariel, I want to go back to your discussion about inhalers and tracheostomies. Now that several manufacturers have added counters to MDIs, the canister no longer easily fits into adapters for tracheostomy use. It restricts the availability of some medications that we can use for children with trachs. I wonder is there any movement in the manufacturing world to make adapters so that we can use the wide range of inhalers available or things that we can do to enhance access to our patients?

Berlinski: A quick answer to that, the AeroTrach Plus has a direct connection for the tracheostomy tube. It's like a regular AeroChamber device, and it has a hole in the back and you put any pMDI that you want. That's one answer.

Panitch: That's OK if the child is breathing spontaneously, but if he or she is attached to a ventilator circuit...

Berlinski: A second option is the AeroChamber Mini. It has an adapter that allows you to use canisters with and without an incorporated counter. Again, I think that you can argue for patients who are ventilated, they can use either system if they are off the ventilator while you deliver aerosols.
I think that the vast majority can, especially those who are at home.

Stokes: A lot of aerosols given to patients with trachs are inhaled steroids, and one of my pet peeves is that many patients get started on inhaled steroids and never get stopped. How do you make the decision to use inhaled steroids in a patient with tracheostomy, all of whom wheeze, and many get put on inhaled steroids without any good clinical evidence of benefit for long-term use?

Berlinski: That's a problem; it's easy to start any drug, and most of the time they are started before they are discharged from the hospital. I have changed my practice. I think that I used more inhaled steroids in the past than I'm using now, especially for that population. I think it depends on response; if I don't see a response to the treatment, then I'll probably discontinue it.

Lin: I have two questions related to vibrating mesh nebulizers; the first is one of your charts about costs put all the cost to the device itself, and in your data about the delivery effectiveness of the drug, there is more drug delivery using the vibrating mesh nebulizers. As the cost for the vibrating mesh nebulizer begins to come down, do you see a point where we'll be able to get patients out of the hospital faster because we're delivering more drug through the vibrating mesh nebulizer, where we would begin to transition to using that preferentially rather than an MDI or small-volume nebulizer just because it's a more effective way to deliver drugs? And if the patient really needs it and they get the drug more effectively, then they presumably should get better faster.

Berlinski: I think that vibrating mesh nebulizers are advantageous for the patient who is hospitalized in the ICU setting and receiving invasive mechanical ventilation. The advantage of the device is that it has no flow, so it doesn't disrupt the $V_{T}$, therefore decreasing barotrauma. The use of a jet nebulizer requires practitioners to decrease the $\mathrm{V}_{\mathrm{T}}$ of the ventilator to lower the risk of barotrauma. On the other hand, if the $\mathrm{V}_{\mathrm{T}}$ is not set back at the prescribed setting once the treatment is completed, the patient will be underventilated. We made a cost comparison based on what we pay at our hospital. ${ }^{1}$ And if you are using it for $28 \mathrm{~d}$ at 4 times/d, it costs about the same. I think that there are things that matter more than cost, but cost has to be incorporated into your variable, because if you are broke you don't have a hospital. In that paper, ${ }^{1}$ we also looked at what happens if instead of giving 2.5, we give 5 or 7.5 ? So we have data that allow you to look at a conventional nebulizer placed in the back of the dry side of the humidifier that is inefficient, but by adding more drug, you would probably do better. The question again is how much drug do you need? I don't think we know. I think there's a tendency to give too much, especially in the emergency department. Everybody starts with $5 \mathrm{mg}$ of albuterol 3 times 20 min apart, and that's probably too much.

Walsh: What's the right mass median aerodynamic diameter (MMAD) for our sized patients? From neonates to adults. We talk about 2 to $5 \mu \mathrm{m}$ being in the adult respirable range, but I feel like it would be much smaller in neonates, yet we don't tend to modify our studies to reflect that.

Berlinski: There are some data that I showed when I talked about transnasal delivery that give you a hint that maybe a smaller MMAD would be better. The only example we have of that in our current practice is inhaled corticosteroids. There are 2 formulations that are 1.2 to $1.3 \mu \mathrm{m}$; then you wonder, do you have to use that? The problem is when you get to more efficient devices, you run the risk of toxicity. Do we use the inefficiency of 
the system to normalize the drug delivery when we vary the size of the patient? We don't change the amount of drug when we go from a 2- to 10$\mathrm{y}$-old patient, we give them the same nebulizer, and we let their breathing pattern and their airway anatomy take care of the difference. Once we start getting very efficient, then I think we run the risk of toxicity and giving them more than they actually need. There is no good answer to the ideal MMAD question, but there are some authors who claim that smaller particle sizes for toddlers and younger children might be better for delivery. Then again, you're going to have to start accounting for reducing the dose, so they don't have these toxic effects.

\section{REFERENCE}

1. Berlinski A, Willis JR. Albuterol delivery by 4 different nebulizers placed in 4 different positions in a pediatric ventilator in vitro model. Respir Care 2013;58(7):1124-1133.

This article is approved for Continuing Respiratory Care Education credit. For information and to obtain your CRCE

(free to AARC members) visit

www.rcjournal.com 